\title{
Application Analysis of Mixed Learning Method of Vocational Education under the Background of "Internet +"
}

\author{
Ping Liu \\ Liaoningjianzhu Vocational College, Liaoning, Liaoyang, 111000
}

Keywords: Internet +, vocational education, mixed learning, analysis research

\begin{abstract}
In the context of "Internet +", the quality of vocational education determines to a certain extent whether China can achieve from the manufacturing power to the creation of a strong country. Therefore, in order to effectively improve the teaching quality of higher vocational education, and to contact the background of the "Internet +" era, higher vocational colleges have successively launched a mixed learning method. However, in the process of actual promotion, the teaching effect of implementing mixed learning in higher vocational colleges is not satisfactory. Based on this phenomenon, this paper links with the background of "Internet +", starting from the definition of mixed teaching and the characteristics of mixed learning in the context of "Internet +", and applying the mixed learning method of vocational education under the background of "Internet +".
\end{abstract}

\section{Introduction}

The main purpose of higher vocational education is to export a large number of high-skilled talents to various enterprises, which also determines that the quality of higher vocational education affects the development of enterprises to a certain extent. At the same time, some of the more powerful enterprises have already realized the automatic mechanization of some production, and the robots have begun to participate in the production of enterprises. This trend also indicates that low-quality workers face the risk of being eliminated by equipment in the future, and the comprehensive quality is strong. Professional skills will become a major requirement. Therefore, the development of higher vocational education in China needs to be reformed and updated to keep up with the pace of the times. In the context of "Internet +", combined with the changing characteristics of the information environment, the teaching method reform, the implementation of hybrid teaching is an important step in higher vocational colleges, but the effect of implementing and promoting the hybrid learning method is not Ideal, so this article explores this.

\section{The Definition of Mixed Learning}

Blended learning is a new way of teaching that combines the advantages of traditional and new teaching methods. At the current stage, hybrid learning adopts a combination of traditional teaching learning methods and online e-learning methods. Traditional teaching methods mainly include blackboard teaching and multimedia teaching methods. Online teaching methods can be divided into full online learning methods (including online course teaching and after-school instruction) and informal online learning methods, such as students watching the network themselves. On the other hand, this paper mainly discusses higher vocational education in the context of "Internet +", so corporate practice and action will also be the teaching content and teaching object of mixed teaching. On the whole, the mixed learning method of vocational education in the context of "Internet + " is a teaching and learning method that combines the advantages of traditional teaching and learning methods, online teaching and learning methods, and enterprise practice and action teaching. 


\section{The Characteristics of Mixed Learning in Vocational Education under the Background of "Internet +"}

In the context of "Internet + ", the form of vocational education will enter the state of mixed learning. This is a paradigm shift, and it is also the trend of the times. From the perspective of technological innovation to promote teaching development, from the initial emergence of traditional teaching, multimedia teaching, to the current information-based teaching, "+ Internet" teaching. Up to now, the teaching method has shown a trend toward "Internet + teaching". The teaching methods and methods brought about by the "Internet +" era will be more intelligent, the teaching ecology will be more open, the teaching structure will be reorganized, the relationship between teachers and students will change, and the relationship between teachers and students will tend to change. Equality, student learning is more ubiquitous, and the individualized needs of students will be more respected and satisfied in the education process. I believe that, first of all, from the perspective of technological change, the biggest difference between the teaching in the context of "Internet +" and the teaching in the "+Internet" era is that the teaching has undergone changes such as "subversive relationship, structural change, and order of magnitude". Secondly, the development of mixed learning based on the "Internet +" background does not mean that any learning method must be "Internet +". In the process of teaching, other traditional teaching forms cannot be completely excluded, and mixed learning should be fully utilized. In the context of "Internet +", traditional face-to-face teaching methods also have their own uniqueness and merits. The situation of these two points has affected the change of learning style, and decided that the learning method will surely enter the stage of mixed learning. The hybrid learning form of online and offline OTO (Online To Offline) has become the inevitable development of the times.

\section{The Mixed Learning Trend of Vocational Education under the Background of "Internet +"}

The so-called OTO is literally the abbreviation of Online To Offline, which is also commonly called "from online to offline." The concept of OTO originated from e-commerce. With the advent of the information age, it has been widely applied and spread to various fields. As far as vocational education and teaching is concerned, OTO refers to a hybrid teaching that fully integrates the complementary interactive advantages of online teaching resources and offline classrooms to meet the individual needs of students. In short, the hybrid learning method is a learning form that combines the face-to-face characteristics of traditional teaching methods with the characteristics of E-learning online learning.

First, mixed learning is not limited to face-to-face teaching in the traditional way of teaching. It improves the monotony of teaching classrooms, the teaching form is relatively simple, and the teaching resources are limited. If it is just online learning, the vast amount of information brought by the Internet lacks teachers. The guidance will lead to a lack of learning goals, low learning efficiency and a vague learning focus. Blended learning combines the advantages of both types of learning, which leads to a combination of online learning and online learning. The learning environment becomes flexible, and students are no longer limited to schools and classrooms. You can start the study by connecting to the Internet in various places such as libraries and dormitories. In addition, students have more independent choices in teaching resources. Students only need to start teaching videos of their own interest to start learning. Online, students can explore the teaching videos in the classroom with teachers and classmates, deepen their own learning and understanding, and promote the process of knowledge internalization.

Second, blended learning combines "learning from resources" with "learning from people". Generally speaking, the ways students learn can be divided into two categories, one is self-learning through teaching resources, and the other is learning from various people including teachers. In the traditional classroom, students mainly learn from "learning from people" and listen to teachers to obtain knowledge. However, teachers' energy and classroom teaching resources have certain limitations, and teachers can't meet the learning needs of each student in the class. Online learning 
can avoid this problem. Internet teaching resources are abundant, and it can limit the bottleneck of single online learning.

Third, mixed learning can effectively expand the participants of learning and greatly enrich the learning style. Traditional classroom participants are limited, and there are three main ways of learning: independent learning, group learning, and class learning. Blended learning, through the China Unicom network, allows more teachers and students to participate in the learning process, thus incorporating the fourth important learning style - "community learning." According to Johnson, the founder of the Horizon Report, "hybrid learning will be the mainstream learning method of the future." He believes that in the field of basic education, people talk about flipping classrooms. In college, they talk about mixed learning, but in fact these two concepts are the same in many ways. Any type of class, whether online or traditional, should have online learning and face-to-face learning. In other words, today's blended learning is organically integrated into information technology. Mixed learning, with a variety of forms of expression, combined with the advantages of traditional teaching and learning, is also an inevitable trend of mixed learning in the context of "Internet +". Hybrid mainly relies on two approaches, technical approaches and teaching models. Not only that, but also in the New Media Alliance's Higher Education Edition 2015 Horizon Report, it is pointed out that "mixed learning" is a recent trend in the development of higher education and will become increasingly popular.

\section{The Application of Mixed Learning Method in Vocational Education under the Background of "Internet +"}

\subsection{Effective Application Method of Mixed Learning in Higher Vocational Education under the Background of "Internet +".}

As a new teaching method, hybrid teaching needs to be gradually explored and practiced in higher vocational education. This also means that the specific application of the hybrid learning method is not universal, and it is different due to the differences of colleges and universities. No matter what kind of learning method, in the process of practice, teachers and students need to participate and promote together. According to the actual situation in the teacher process, different measures and strategies are adopted to adjust. The following is my occupation in the background of "Internet +". Application exploration of educational hybrid learning methods:

First of all, the process-oriented approach should be used to guide the implementation of mixed learning, that is, the process-oriented vocational education thought as the guiding principle, combined with online education, school teaching and enterprise practice as a systematic unified teaching task, these three Cooperate and supplement. To be specific, it is a form of learning organization that is a key to mixing process tasks. Since higher vocational education is the main teaching goal of cultivating high-skilled personnel, the promotion of professional process ability and the transfer of professional process knowledge are the teaching tasks, and the process tasks are also integrated into the knowledge of professional process and occupational process, which also leads to the process task. Many of the inevitable factors will have a certain degree of impact on the process tasks, resulting in differences in the difficulty and effect of the process tasks. Therefore, in the teaching process, the process task needs to be decomposed into several sub-task implementations, which reduces the difficulty of process task implementation.

Secondly, it is necessary to mix design teaching activities and curriculum arrangements based on a complete professional process cycle. The career process should be based on the action process as a core. Higher vocational education is committed to cultivating students' ability to actively construct and design work processes. This also determines that students' understanding and hands-on ability in action time is not improved by the complete perception of theoretical knowledge. This process needs to be improved. Students can participate in and participate in the entire work process in order to acquire complete knowledge and ability, so as to cultivate the ability to cultivate, improve, evaluate and enhance the work process. At present, the teaching methods of teaching activities can be divided into three main categories: task-based teaching activities, experiential teaching activities 
and autonomous teaching activities. The realization and completion of a complete professional process task requires the integration of multiple forms of teaching activities and mixed design.

Finally, hybrid learning is inseparable from the teaching resources and information sharing support based on the Internet platform, that is, the complete teaching situation created by the three teaching videos, teaching tasks and teaching activities provided by the online course platform provides favorable support for teaching activities. .

In addition, there are many implementation methods for implementing mixed learning in higher vocational education, which is not limited to the guidance of process-oriented law. Other methods still need to be further explored and discovered in the process of advancing practice, and it is necessary to accumulate corresponding teaching experience to improve and improve.

\subsection{Effective Ways of Mixed Learning in Higher Vocational Education under the Background of "Internet +".}

Higher vocational education aims at cultivating and exporting high-quality and highly skilled personnel. Therefore, in addition to having a certain level of theoretical knowledge, students in higher vocational education also need to have higher skills and operational skills. In this way, online learning takes up an important part of the mixed teaching of school teaching, online learning and corporate practice. In this regard, in the teaching approach of promoting vocational learning in higher vocational education, the quality of online learning directly affects the learning effect of mixed learning. Therefore, higher vocational colleges need to invest more in online teaching resources to improve the quality of online teaching, and the quality of learning in mixed learning can be further improved.

In the process of online learning, students' participation should be designed and optimized according to the student's participation process. That is, through the complete process of whether the student starts to learn the task to participate in the learning activity and whether to cooperate. In this way, the learning efficiency of hybrid learning can be optimized by improving the quality of online learning, and the advantages of school teaching, business practice and network teaching are enhanced.

\section{Conclusion}

In summary, this paper analyzes the definition of mixed learning, the characteristics and learning trends of mixed-education in vocational education under the background of "Internet +", and combines the above analysis to summarize the mixed vocational education under the background of "Internet +".

\section{References}

[1] Hu Xiaoyong, Ji Haozhen. Embracing mixed learning, calmly deal with "Internet +" [J]. China Information Technology Education, 2016, (5): 4-4. DOI: 10.3969/j.issn.1674-2117.2016 .05.002.

[2] Yu Wei. Research on the Application of Mixed Learning Method in Vocational Education under the Environment of Internet + [J]. Modern economic information, 2017(16):392-393

[3] Zhang Letian. Research on the Application of Vocational Education Teaching Mode from the Perspective of "Internet +"[J]. China Vocational and Technical Education, 2016(26): 93-96

[4] Wang Xiwei. Discussion on the Teaching Mode of Vocational Education under the Internet + Times [J]. Business, 2017 (49)

[5] Wang Zhiwei. Research on the New Mode of Higher Vocational Classroom Teaching in the Age of "Internet +"[J]. Contemporary Vocational Education, 2016 (9):45-48 